\title{
Desenvolvimento inicial do amendoinzeiro sob diferentes densidades de matocompetição com Urochloa
}

\author{
Lucas Aparecido Manzani Lisboa ${ }^{1}$, Ronaldo da Silva Viana ${ }^{1}$, Filipe Virgílio Ribeiro ${ }^{1}$, Paulo \\ Alexandre Monteiro de Figueiredo ${ }^{1}$, Sérgio Bispo Ramos ${ }^{1}$
}

\begin{abstract}
${ }^{1}$ Universidade Estadual Paulista, Faculdade de Ciências Agrárias e Tecnológicas, Dracena, São Paulo, Brasil. E-mail: lucas.lisboa@unesp.br, ronaldo.viana@unesp.br, filipevirgilioribeiro@gmail.com, paulo.figueiredo@unesp.br, sergio.bispo@unesp.br
\end{abstract}

Recebido: 18/05/2017; Aceito: 25/01/2019.

\begin{abstract}
RESUMO
Gramíneas e leguminosas competem nos sistemas produtivos, sendo que esta competição depende de suas habilidades específicas para a sua sobrevivência. O objetivo desse trabalho foi avaliar o desenvolvimento inicial de amendoinzeiro sob diferentes densidades de matocompetição com Urochloa. Foi realizado um experimento com delineamento inteiramente casualizado, em esquema fatorial $4 \times 5$. O primeiro fator foi composto por quatro tipos de gramíneas, ou seja, Urochloa brizantha cv. Paiaguás, Marandu, Piatã e Urochloa ruziziensis; o segundo, por cinco densidades de matocompetição e cinco repetições, totalizando 100 parcelas ou vasos. Após 30 dias da semeadura, foram determinados os seguintes parâmetros: ISPADA - índice spad do amendoim; CEA condutância estomática do amendoim; DCA - diâmetro de caule do amendoim; APA e APG - altura de planta do amendoim e gramínea; MSPAA e MSPAG - massa seca da parte aérea do amendoim e gramínea; e MSRA e MSRG - massa seca de raiz do amendoim e gramínea. O amendoinzeiro responde de maneira negativa quando submetido a altas densidades de matocompetição com gramíneas do gênero Urochloa. A Urochloa ruziziensis apresentou uma maior matocompetição no desenvolvimento inicial do amendoinzeiro.
\end{abstract}

Palavras-chave: Arachis hypogaea; estresse; Paiaguás; Marandu; Piatã.

\section{Initial development amendoinzeiro under different matocompetition densities with Urochloa}

\begin{abstract}
Grasses and legumes compete in productive systems, and this competition depends on their specific survival skills. The objective of this work was to evaluate the initial development of peanut under different densities of competition with Urochloa. An experiment was carried out with a completely randomized design, in a 4 x 5 factorial scheme. The first factor was composed of four types of grasses, that is, Urochloa brizantha cv. Paiaguás; Marandu; Piatã and Urochloa ruziziensis, the second factor was composed of five densities of weed competition and five replications, totalizing 100 plots or vessels. After 30 days of sowing, the following parameters were determined: ISPADA - peanut spad index; CEA - stomatal peanut conductance; DCA - peanut stem diameter; APA and APG - plant height of peanut and grass; MSPAA and MSPAG - dry mass of aerial part of peanut and grass and MSRA and MSRG - dry mass of peanut root and grass. The peanut tree responds negatively when subjected to high weed competition densities with grasses of the genus Urochloa. Urochloa ruziziensis showed a greater weed competition in the initial development of the peanut tree.
\end{abstract}

Keywords: Arachis hypogaea; stress; Paiaguás; Marandu; Piatã. 


\section{Introdução}

$\mathrm{O}$ amendoim (Arachis hypogaea), pertencente à família fabaceae, assim como o feijão e a soja, é uma das principais culturas oleaginosas de âmbito nacional e mundial (Santos et al., 2012). Entretanto, gramíneas e leguminosas competem, nos sistemas produtivos, por fontes de água, nitrogênio, outros minerais do solo, sendo que esta competição depende de suas habilidades específicas para sobreviver. Esta produtividade pode ser reduzida pela presença de plantas daninhas, que interferirão no crescimento, no desenvolvimento de plantas, na produtividade, além de outros fatores bióticos (Santos et al., 2010; Parreira et al., 2011).

O efeito da competição das plantas daninhas no rendimento das culturas é influenciado tanto pela habilidade competitiva, quanto pela densidade de infestação sob a cultura. Estes efeitos de competição entre as espécies são influenciados pelas condições ambientais em que estão inseridos, tais como: o clima, a fertilidade do solo e até mesmo as práticas de manejo (Heemst, 1986). É de grande importância o entendimento das respostas das culturas sob o efeito da intensidade da matocompetição, a fim de garantir uma tomada de decisão correta no controle das plantas invasoras.

Os fatores que afetam o grau de interferência entre as culturas agrícolas e a comunidade infestante podem ser ligados à cultura (espécie, espaçamento e densidade de plantio), à comunidade infestante (composição específica, densidade e distribuição) e ao ambiente (Bleasdale, 1960). Dependerá, também, da época e extensão do período de convivência (Pitelli, 1985). Dentre estes fatores, deve-se destacar a importância do espaçamento, já que o mesmo atua sobre a precocidade e intensidade de sombreamento da cultura sobre as plantas daninhas.

O objetivo desse trabalho foi avaliar o desenvolvimento inicial do amendoinzeiro sob diferentes densidades de matocompetição com Urochloa.

\section{Material e Métodos}

O experimento foi conduzido em Dracena, Estado de São Paulo, durante o mês de outubro de 2016, em casa de vegetação, na Faculdade de Ciências Agrárias e Tecnológicas da Universidade Estadual Paulista Júlio de Mesquita Filho.

Foi utilizado o delineamento inteiramente casualizado, em esquema fatorial duplo $4 \times 5$. O primeiro fator foi composto por quatro tipos de gramíneas, ou seja, Urochloa brizantha cv. Paiaguás, Marandu, Piatã e Urochloa ruziziensis; o segundo, por cinco densidades de matocompetição e cinco repetições, totalizando 100 parcelas ou vasos.
As densidades de matocompetição foram compostas por: ausência da gramínea, ou seja, apenas o plantio do amendoim; baixa densidade de plantio das gramíneas, onde foi considerada a presença de três gramíneas por vaso, disponibilizando $163,53 \mathrm{~cm}^{2}$ por planta. Para as condições de média densidade de plantio, foi considerada a presença de seis gramíneas por vaso, disponibilizando $81,76 \mathrm{~cm}^{2}$ por planta. Em condições de alta densidade de plantio, foi considerada a presença de nove gramíneas por vaso, sendo $54,51 \mathrm{~cm}^{2}$ por planta. E para as condições de densidade de plantio muito alta foi considerada a presença de doze gramíneas por vaso, sendo $40,88 \mathrm{~cm}^{2}$ por planta.

$\mathrm{Na}$ profundidade de $3 \mathrm{~cm}$ foi realizado o plantio de uma semente de amendoim (Arachis hypogaea L.), variedade Alto oleica, em vasos com capacidade volumétrica de $9 \mathrm{dm}^{3}$ e 490,6 $\mathrm{cm}^{2}$ de área, preenchidos com Argissolo proveniente da camada de 0-0,3 m, previamente peneirado e adubado conforme Raij et al. (1996). Na mesma ocasião, foram semeadas a dois $\mathrm{cm}$ de profundidade as sementes de Urochloa sp. com suas respectivas densidades. Durante o período de condução do experimento, os vasos foram irrigados sempre que necessário, respeitando a capacidade de campo.

Após 30 dias da semeadura, foram determinados os seguintes parâmetros: ISPADA - índice spad do amendoim, determinado através da leitura direta do medidor digital modelo CCM-200; CEA - condutância estomática do amendoim, determinada pela leitura direta no aparelho porômetro modelo AP-4; DCA diâmetro de caule do amendoim, determinado através do uso de um paquímetro graduado em milímetros; APA e APG - altura de planta do amendoim e gramínea, determinada através do uso de uma régua graduada em milímetros; MSPAA e MSPAG - massa seca da parte aérea do amendoim e gramínea; MSRA e MSRG massa seca de raiz do amendoim e gramínea, determinada através da secagem da massa úmida em estufa de circulação e renovação de ar em temperatura constante de $65^{\circ} \mathrm{C}$, até atingirem peso constante.

Os parâmetros foram submetidos à análise de variância pelo teste $\mathrm{F}(\mathrm{p}<0,05)$ e suas médias comparadas pelo teste de Tukey a $5 \%$ de probabilidade, sendo utilizado o programa Assistat 7.6 Beta (Silva e Azevedo, 2002).

\section{Resultados e Discussão}

Foi observada uma diferença estatística no parâmetro índice spad do amendoim quando submetido a diferentes densidades de matocompetição com as gramíneas $U$. brizantha cv. Paiaguás com densidade muito alta, ou seja, doze plantas por vaso, seguida do cultivar Piatã com a densidade alta, sendo nove plantas por vaso, onde proporcionaram menores índices spad na 
cultura do amendoim, conforme demonstrado na Tabela 1. Para Ratnakumar e Vadez (2011), variedades de amendoim mais adaptadas a condições de déficit hídrico ou luminoso desenvolvem estratégias através da redução da sua área foliar, porém aumentam as concentrações de clorofilas no seu conteúdo intracelular através do efeito de compensação para esses danos (Tellah et al., 2014; Graciano et al., 2011).

No parâmetro altura de planta do amendoim (APA), foi encontrada uma diferença estatística entre os fatores. A gramínea $U$. brizantha cv. Piatã ocasionou um menor crescimento da parte aérea do amendoim, e quando a cultura foi submetida a uma densidade muito alta, conforme demonstrado na Tabela 1. Essa resposta de menor crescimento do amendoim pode ser um indicativo na associação dos efeitos danosos causados pela competição entre plantas, entre eles o índice spad, que possui alta correlação com o índice de clorofila (Sharwood et al., 2016; Sant'Ana et al., 2010), o que pode ter diminuído a taxa fotossintética e a condutância estomática.

Houve uma interação significativa entre os fatores cultivares de gramíneas $\mathrm{x}$ densidade no parâmetro condutância estomática do amendoim, conforme apresentado na Tabela 2.

Quando o amendoim foi submetido a uma matocompetição com densidade muito alta de $U$. ruziziensis, ocasionou uma redução na condutância estomática com 149,00 mmol m $\mathrm{m}^{-2} \mathrm{~s}^{-1}$. Uma menor condutância estomática é um indicativo de que o vegetal diminuiu a sua transpiração devido ao fechamento dos seus estômatos, que pode ocasionar uma queda na fixação de carbono atmosférico na sua massa seca (Graciano et al. 2011).

Tabela 1. Valores médios dos parâmetros ISPADA - índice spad do amendoim; CE - condutância estomática do amendoim; DCA diâmetro de caule do amendoim; APA - altura de planta do amendoim; MSTPAA - massa seca da parte aérea do amendoim e MSRA - massa seca de raiz do amendoim quando submetido a diferentes densidades de matocompetição.

\begin{tabular}{|c|c|c|c|c|c|c|}
\hline & ISPADA & 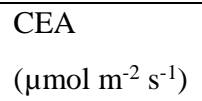 & $\begin{array}{l}\text { DCA } \\
(\mathrm{cm})\end{array}$ & $\begin{array}{l}\text { APA } \\
(\mathrm{cm})\end{array}$ & $\begin{array}{l}\text { MSPAA } \\
(\mathrm{g})\end{array}$ & $\begin{array}{l}\text { MSRA } \\
(\mathrm{g})\end{array}$ \\
\hline \multicolumn{7}{|l|}{ Gramínea (G) } \\
\hline Paiaguás & $31,81 \mathrm{~b}$ & $234,44 \mathrm{ab}$ & $0,34^{\mathrm{a}}$ & $20,12 b$ & $3,51 \mathrm{c}$ & $1,59 \mathrm{a}$ \\
\hline Marandu & $42,63 a$ & $296,28 \mathrm{a}$ & $0,24 b$ & $25,74 \mathrm{a}$ & $1,12 \mathrm{~d}$ & $0,65 c$ \\
\hline Piatã & $37,39 \mathrm{ab}$ & $219,64 b$ & $0,33^{\mathrm{a}}$ & $17,12 \mathrm{c}$ & $5,61 b$ & $0,47 \mathrm{c}$ \\
\hline U. ruziziensis & $39,64 a$ & $269,96 \mathrm{ab}$ & $0,21 \mathrm{~b}$ & $26,12 \mathrm{a}$ & $11,91 \mathrm{a}$ & $0,90 \mathrm{~b}$ \\
\hline DMS & 7,23 & 65,50 & 0,04 & 2,61 & 1,49 & 0,23 \\
\hline \multicolumn{7}{|l|}{ Densidade (D) } \\
\hline Ausência & $40,71 \mathrm{a}$ & $260,50 \mathrm{ab}$ & $0,32^{\mathrm{a}}$ & $23,78 \mathrm{a}$ & $8,92 a$ & $1,22 \mathrm{a}$ \\
\hline Baixa & $41,02 \mathrm{a}$ & $300,10 \mathrm{a}$ & $0,31^{\mathrm{a}}$ & $23,25 \mathrm{a}$ & $6,59 b$ & $1,09 \mathrm{a}$ \\
\hline Média & $35,99 \mathrm{a}$ & $267,25 \mathrm{ab}$ & $0,26 \mathrm{ab}$ & $22,22 \mathrm{a}$ & $4,43 \mathrm{c}$ & $0,73 b$ \\
\hline Alta & $38,53 \mathrm{a}$ & $236,50 \mathrm{ab}$ & $0,27 \mathrm{ab}$ & $23,41 \mathrm{a}$ & $4,08 \mathrm{c}$ & $0,77 \mathrm{~b}$ \\
\hline Muito alta & $33,09 \mathrm{a}$ & $211,06 \mathrm{~b}$ & $0,24 b$ & $18,72 b$ & $3,66 \mathrm{c}$ & $0,70 \mathrm{~b}$ \\
\hline DMS & 8,59 & 77,86 & 0,05 & 3,11 & 1,77 & 0,27 \\
\hline$F(G)$ & $5,5122 * *$ & $3,8600^{*}$ & $22,5015^{* *}$ & $38,9723 * *$ & $132,8661 * *$ & $61,5940^{* *}$ \\
\hline $\mathrm{F}(\mathrm{D})$ & $2,3602 \mathrm{~ns}$ & $2,8866^{*}$ & $5,1263 * *$ & $6,9072 * *$ & $24,1048 * *$ & $11,2581 * *$ \\
\hline $\mathrm{F}(\mathrm{GxD})$ & $1,0710 \mathrm{~ns}$ & $2,3010^{*}$ & $3,0140 * *$ & $1,2103 \mathrm{~ns}$ & $11,5893 * *$ & $1,8203 \mathrm{~ns}$ \\
\hline $\mathrm{CV} \%$ & 25,71 & 34,56 & 23,55 & 15,81 & 36,20 & 34,72 \\
\hline
\end{tabular}

Tabela 2. Desdobramento da interação dos fatores cultivares de gramíneas em função da densidade de plantas invasoras no parâmetro condutância estomática do amendoim (CEA) em $\mu \mathrm{mol} \mathrm{m} \mathrm{m}^{-2} \mathrm{~s}^{-1}$.

\begin{tabular}{|c|c|c|c|c|c|}
\hline & \multicolumn{5}{|c|}{ Densidade de plantas invasoras (D) } \\
\hline & Ausência & Baixa & Média & Alta & Muito alta \\
\hline \multicolumn{6}{|l|}{ Gramínea (G) } \\
\hline Paiaguás & $275,40 \mathrm{aA}$ & $289,80 \mathrm{abA}$ & $244,80 \mathrm{aA}$ & $184,20 \mathrm{aA}$ & $178,00 \mathrm{abA}$ \\
\hline Marandu & $210,60 \mathrm{aB}$ & $419,60 \mathrm{aA}$ & $256,00 \mathrm{aB}$ & $291,80 \mathrm{aAB}$ & $303,00 \mathrm{aAB}$ \\
\hline Piatã & $260,00 \mathrm{aA}$ & $182,00 \mathrm{bA}$ & $222,40 \mathrm{aA}$ & $220,00 \mathrm{aA}$ & $213,84 \mathrm{abA}$ \\
\hline \multirow[t]{2}{*}{ U. ruziziensis } & $296,00 \mathrm{aAB}$ & $309,00 \mathrm{abA}$ & $345,80 \mathrm{aA}$ & $250,00 \mathrm{aAB}$ & $149,00 \mathrm{bB}$ \\
\hline & DMSCol: 14 & \multicolumn{4}{|c|}{ DMSLin: 155,73} \\
\hline
\end{tabular}

As médias seguidas pela mesma letra minúscula na coluna não diferem estatisticamente entre si. As médias seguidas pela mesma letra maiúscula na linha não diferem estatisticamente entre si. Foi aplicado o Teste de Tukey ao nível de 5\% de probabilidade. 
Na Tabela 3, está apresentada a interação significativa entre os fatores cultivares de gramíneas $\mathrm{x}$ densidade de plantas no parâmetro diâmetro de caule do amendoim. A matocompetição começou a apresentar um efeito danoso a partir de uma densidade baixa, acentuando-se com as demais densidades com a gramínea U. ruziziensis. Segundo Barbieri et al. 2016, o amendoim possui adaptações fisiológicas que possibilitam o seu desenvolvimento em condições ambientais adversas, o que ocasiona uma mudança na arquitetura da planta. Essas respostas ambientais levam ao aumento ou mesmo diminuição do diâmetro de caule das plantas cultivadas. Bellettini e Endo (2001), estudando o comportamento do amendoim em diferentes espaçamentos e densidades de plantio, apresentaram resultados semelhantes aos desse trabalho, que necessita de estudos mais aprofundados quanto às respostas da cultura em situação de competição entre plantas (Heemst, 1986).

$\mathrm{Na}$ Tabela 4, está apresentada a interação significativa entre os fatores cultivares de gramíneas em função da densidade de planta no parâmetro massa seca da parte aérea do amendoim (MSPAA). O amendoim apresentou maior incremento na massa seca da parte aérea quando semeado na ausência das gramíneas. As respostas negativas quanto à competição entre o amendoim e as gramíneas já eram esperadas, pois se trata de espécies com características fisiológicas e morfológicas distintas, o que evidencia os efeitos danosos causados pela matocompetição entre elas.

Segundo Vidal e Merotto Júnior (2001), os danos causados pela matocompetição podem chegar a 70\%, o que corrobora com os resultados encontrados nesse trabalho, pois os danos causados pela matocompetição em alta densidade de plantas invasoras chegaram a aproximadamente $93 \%$ na cultura do amendoim.

De maneira análoga, no parâmetro massa seca de raiz do amendoim (MSRA) foi encontrada uma diferença significativa entres os fatores, porém de maneira isolada. A Urochloa brizantha cv. Marandu e Piatã ocasionaram maiores danos ao amendoinzeiro, quando o mesmo foi submetido a partir de uma alta densidade de plantas invasoras; suas raízes apresentaram menores valores médios.

Quanto ao desenvolvimento das gramíneas, na Tabela 5 estão apresentados os valores médios de altura de planta das gramíneas (APG); massa seca da parte aérea das gramíneas (MSPAG) e massa seca de raiz das gramíneas (MSRG). Para o parâmetro altura de planta das gramíneas (APG) foi observada uma diferença estatística apenas no fator tipo de gramínea, ou seja, a $U$. ruziziensis seguida da $U$. brizantha cv. Marandu apresentaram plantas mais altas, com médias de 62,70 e $58,25 \mathrm{~cm}$, respectivamente. Esse resultado já era esperado devido ao fato de o crescimento dessas duas espécies de gramíneas ser maior, o que exigiu que o amendoim gastasse suas energias para competir com as mesmas na busca por luz, culminando no efeito de estiolamento do amendoim, conforme demonstrado na Tabela 1. Miranda et al. (2010), quando estudaram o cultivo do amendoim sob ambiente protegido por diferentes coberturas plásticas, constaram o efeito da interferência da radiação sobre a cultura, o que torna um fator limitante para seu crescimento, pois a intensidade e qualidade luminosa está associada ao estiolamento da cultura. Esse fator quantidade e qualidade luminosa explica a ação do sombreamento que o amendoinzeiro sofreu quando submetido à competição com as espécies de gramíneas.

Foi observada uma interação entre os fatores no parâmetro massa seca da parte aérea das gramíneas (MSPAG), conforme demonstrado na Tabela 6. Quando houve uma baixa densidade de gramíneas, $U$. brizantha cv. Marandu e $U$. ruziziensis apresentaram maiores valores em relação às demais cultivares. Porém, todas as gramíneas se igualaram estatisticamente somente quando houve uma densidade muito alta dessas plantas, o que já era esperado devido ao maior número de plantas em uma mesma área. Uma densidade muito alta das gramíneas não foi suficiente para interferir no desenvolvimento das mesmas, o que torna necessário mais estudos para a determinação do limite máximo de densidade que essas plantas suportam.

Freitas et al. (2013), quando estudaram o cultivo do milho consorciado com $U$. ruziziensis, constataram que a densidade de plantio da cultura influenciou no desenvolvimento da gramínea, que de maneira análoga à Urochloa sp. no presente trabalho, se desenvolveu em densidade alta e consequentemente afetou o crescimento do amendoim (Tabela 1). Silva et al. (2013), estudando o desempenho da $U$. ruziziensis consorciada com a cultura do soja, observaram esse efeito de competição entre as espécies, principalmente pela disputa da luz, pois essa interferência limita a taxa fotossintética, resultando na diminuição da massa seca das culturas sob matocompetição. Foi observada uma interação entre os fatores no parâmetro massa seca da raiz das gramíneas, conforme demonstrado na Tabela 7. O desenvolvimento das raízes apresentou uma semelhança com o parâmetro MSPAG. Na densidade muito alta, as gramíneas $U$. ruziziensis e $U$. brizantha $\mathrm{cv}$. Paiaguás foram iguais estatisticamente, apresentando uma média de 14,96 e 11,93 gramas, respectivamente.

Um bom desenvolvimento de raiz é fundamental para o estabelecimento da cultura no seu substrato, garantindo maior absorção de nutrientes e água, o que pode proporcionar maior desenvolvimento da parte aérea. Quando ocorre a matocompetição nas fases iniciais das culturas, esse desenvolvimento passa a ser comprometido. 
Tabela 3. Desdobramento da interação dos fatores cultivares de gramíneas em função da densidade de planta no parâmetro diâmetro de caule do amendoim.

\begin{tabular}{llllll}
\hline & \multicolumn{4}{c}{ Densidade de plantas invasoras (D) } \\
Gramínea $(\mathrm{G})$ & Ausência & Baixa & Média & Alta & Muito alta \\
\cline { 2 - 5 } Paiaguás & $0,26 \mathrm{aB}$ & $0,38 \mathrm{aA}$ & $0,34 \mathrm{aAB}$ & $0,36 \mathrm{aAB}$ & $0,36 \mathrm{aAB}$ \\
Marandu & $0,34 \mathrm{aA}$ & $0,26 \mathrm{bAB}$ & $0,22 \mathrm{bB}$ & $0,22 \mathrm{bcB}$ & $0,20 \mathrm{bB}$ \\
Piatã & $0,37 \mathrm{aA}$ & $0,38 \mathrm{aA}$ & $0,34 \mathrm{aAB}$ & $0,33 \mathrm{abAB}$ & $0,23 \mathrm{bB}$ \\
U. ruziziensis & $0,31 \mathrm{aA}$ & $0,24 \mathrm{bAB}$ & $0,17 \mathrm{bB}$ & $0,17 \mathrm{cB}$ & $0,17 \mathrm{bB}$ \\
\hline & DMSCol: 0,11 & & DMSLin: 0,11 & & \\
\hline
\end{tabular}

As médias seguidas pela mesma letra minúscula na coluna não diferem estatisticamente entre si. As médias seguidas pela mesma letra maiúscula na linha não diferem estatisticamente entre si. Foi aplicado o Teste de Tukey ao nível de 5\% de probabilidade.

Tabela 4. Desdobramento da interação dos fatores cultivares de gramíneas em função da densidade de plantas no parâmetro massa seca da parte aérea do amendoim (MSPAA).

\begin{tabular}{|c|c|c|c|c|c|}
\hline & \multicolumn{5}{|c|}{ Densidade de plantas invasoras (D) } \\
\hline & Ausência & Baixa & Média & Alta & Muito alta \\
\hline \multicolumn{6}{|l|}{ Gramínea (G) } \\
\hline Paiaguás & $3,52 \mathrm{cA}$ & $3,73 \mathrm{cA}$ & $3,36 \mathrm{bcA}$ & $3,41 \mathrm{bA}$ & $3,52 \mathrm{bA}$ \\
\hline Marandu & $1,71 \mathrm{cA}$ & $1,16 \mathrm{cA}$ & $1,03 \mathrm{cA}$ & $1,13 \mathrm{bA}$ & $0,59 \mathrm{bA}$ \\
\hline Piatã & $8,26 \mathrm{bA}$ & $8,51 \mathrm{bA}$ & $5,92 \mathrm{abAB}$ & $4,13 \mathrm{bBC}$ & $1,24 \mathrm{bC}$ \\
\hline \multirow[t]{2}{*}{ U. ruziziensis } & $22,20 \mathrm{aA}$ & $12,96 \mathrm{aB}$ & $7,41 \mathrm{aC}$ & $7,67 \mathrm{aC}$ & $9,30 \mathrm{aC}$ \\
\hline & DMSCol: & & DMSLin: 3 & & \\
\hline
\end{tabular}

As médias seguidas pela mesma letra minúscula na coluna não diferem estatisticamente entre si. As médias seguidas pela mesma letra maiúscula na linha não diferem estatisticamente entre si. Foi aplicado o Teste de Tukey ao nível de 5\% de probabilidade.

Tabela 5. Valores médios dos parâmetros APG - altura de planta das gramíneas; MSPAG - massa seca da parte aérea das gramíneas; MSRG - massa seca de raiz das gramíneas quando submetidos às diferentes densidades de matocompetição.

\begin{tabular}{|c|c|c|c|}
\hline & $\begin{array}{l}\text { APG } \\
(\mathrm{cm})\end{array}$ & $\begin{array}{l}\text { MSPAG } \\
(\mathrm{g})\end{array}$ & $\begin{array}{l}\text { MSRG } \\
(\mathrm{g})\end{array}$ \\
\hline \multicolumn{4}{|l|}{ Gramínea (G) } \\
\hline Paiaguás & $55,16 \mathrm{~b}$ & $6,08 \mathrm{c}$ & $7,65 b$ \\
\hline Marandu & $58,25 \mathrm{ab}$ & $8,49 b$ & $6,36 b$ \\
\hline Piatã & $51,94 \mathrm{~b}$ & $6,30 \mathrm{c}$ & $5,28 \mathrm{~b}$ \\
\hline U. ruziziensis & $62,70 \mathrm{a}$ & $10,49 \mathrm{a}$ & $12,72 \mathrm{a}$ \\
\hline DMS & 7,47 & 1,65 & 2,43 \\
\hline \multicolumn{4}{|l|}{ Densidade (D) } \\
\hline Ausência & ---- & --- & --- \\
\hline Baixa & $55,91 \mathrm{a}$ & $3,60 \mathrm{~d}$ & $3,51 \mathrm{c}$ \\
\hline Média & $58,43 \mathrm{a}$ & $6,54 \mathrm{c}$ & $7,64 b$ \\
\hline Alta & $56,09 \mathrm{a}$ & $9,36 \mathrm{~b}$ & $10,69 \mathrm{a}$ \\
\hline Muito alta & $57,61 \mathrm{a}$ & $11,87 \mathrm{a}$ & $10,19 \mathrm{a}$ \\
\hline DMS & 7,47 & 1,65 & 2,43 \\
\hline $\mathrm{F}(\mathrm{G})$ & $5,2474 * *$ & $21,8224 * *$ & $25,3781 * *$ \\
\hline $\mathrm{F}(\mathrm{D})$ & $0,3686 \mathrm{~ns}$ & $64,5971 * *$ & $25,2062 * *$ \\
\hline $\mathrm{F}(\mathrm{GxD})$ & $1,2222 \mathrm{~ns}$ & $2,1713^{*}$ & $5,1302 * *$ \\
\hline $\mathrm{CV} \%$ & 15,69 & 25,33 & 36,49 \\
\hline
\end{tabular}

Tabela 6. Desdobramento da interação dos fatores cultivares de gramíneas em função da densidade de planta no parâmetro massa seca da parte aérea das gramíneas.

\begin{tabular}{lllll}
\hline & & \multicolumn{2}{c}{ Densidade de plantas invasoras (D) } & Muito alta \\
\cline { 2 - 4 } Gramínea $(\mathrm{G})$ & & Média & Alta & $11,30 \mathrm{aA}$ \\
Paiaguás & $2,48 \mathrm{bC}$ & $4,37 \mathrm{bcBC}$ & $6,18 \mathrm{bB}$ & $12,45 \mathrm{aa}$ \\
Marandu & $3,86 \mathrm{abB}$ & $7,12 \mathrm{bB}$ & $10,55 \mathrm{aA}$ & $10,92 \mathrm{aA}$ \\
Piatã & $2,16 \mathrm{bB}$ & $3,40 \mathrm{cB}$ & $8,72 \mathrm{abA}$ & $12,83 \mathrm{aA}$ \\
$U$. ruziziensis & $5,90 \mathrm{aB}$ & $11,26 \mathrm{aA}$ & $11,98 \mathrm{aA}$ & DMSLin: 3,31 \\
\hline
\end{tabular}

As médias seguidas pela mesma letra minúscula na coluna não diferem estatisticamente entre si. As médias seguidas pela mesma letra maiúscula na linha não diferem estatisticamente entre si. Foi aplicado o Teste de Tukey ao nível de 5\% de probabilidade. 
Tabela 7. Desdobramento da interação dos fatores cultivares de gramíneas em função da densidade de planta no parâmetro massa seca da raiz das gramíneas.

\begin{tabular}{|c|c|c|c|c|}
\hline & \multicolumn{4}{|c|}{ Densidade de plantas invasoras (D) } \\
\hline & Baixa & Média & Alta & Muito alta \\
\hline \multicolumn{5}{|l|}{ Gramínea (G) } \\
\hline Paiaguás & $2,76 \mathrm{aC}$ & 9,62abAB & $6,30 \mathrm{bBC}$ & $11,93 \mathrm{abA}$ \\
\hline Marandu & $3,61 \mathrm{aB}$ & $4,80 \mathrm{bcAB}$ & $8,11 \mathrm{bAB}$ & $8,92 \mathrm{bcA}$ \\
\hline Piatã & $3,43 \mathrm{aB}$ & $3,75 \mathrm{cB}$ & $9,02 \mathrm{bA}$ & $4,94 \mathrm{cAB}$ \\
\hline \multirow[t]{2}{*}{ U. ruziziensis } & $4,24 \mathrm{aC}$ & $12,38 \mathrm{aB}$ & $19,32 \mathrm{aA}$ & $14,96 \mathrm{aAB}$ \\
\hline & DMSCo & & DMSLin: & \\
\hline
\end{tabular}

As médias seguidas pela mesma letra minúscula na coluna não diferem estatisticamente entre si. As médias seguidas pela mesma letra maiúscula na linha não diferem estatisticamente entre si. Foi aplicado o Teste de Tukey ao nível de 5\% de probabilidade.

As plantas com maior índice de raízes no solo garantem maior resistência ao estresse hídrico em períodos de veranico (Castro et al. 2009). Esse efeito danoso causado pela competição entre mesmas espécies ou entre espécies diferentes foi bem definido (Tabela 1), em que o desenvolvimento das raízes do amendoim foi prejudicado com competição por espaço com as gramíneas.

$\mathrm{O}$ entendimento das respostas das culturas sob o efeito da intensidade da matocompetição é importante para tomada de decisões para controle das plantas invasoras, a fim de garantir o máximo de produtividade.

\section{Conclusões}

$\mathrm{O}$ amendoinzeiro responde de maneira negativa quando submetido a altas densidades de matocompetição com gramíneas do gênero Urochloa.

A Urochloa ruziziensis apresentou uma maior matocompetição no desenvolvimento inicial do amendoinzeiro.

\section{Referências Bibliográficas}

Barbieri, J.D., Dallacort, R., Faria Júnior, C.A., Freitas, P.S. L., Fenner, W., 2016. Ensaio de épocas e densidade de plantas de duas cultivares de amendoim. Nucleus, 13(1), 111-121.

Bellettini, N.M.T., Endo, R.M., 2001. Comportamento do amendoim "das águas", Arachis hypogaea L., sob diferentes espaçamentos e densidades de semeadura. Acta Scientiarum, 23(5), 1249-1256.

Bleasdale, J.K.A., 1960. Studies on plant competition, in: Harper, J.L., (Ed.), The biology of weeds. Oxford, Blackweel Scientific, pp. 133-42.

Castro, E.M., Pereira, F.J., Paiva, R., 2009. Histologia vegetal: estrutura e função de órgãos vegetativos. Lavras-MG, Universidade Federal de Lavras.

Freitas, R.J., Nascente, A.S., Santos, F.L.S., 2013. População de plantas de milho consorciado com Urochloa ruziziensis. Pesquisa Agropecuária Tropical, 43(1), 79-87.

Graciano, E.S., Nogueira, R.J.M.C., Lima, D.R.M., Pacheco, C.M., Santos, R.C., 2011. Crescimento e capacidade fotossintética da cultivar de amendoim BR 1 sob condições de salinidade. Revista Brasileira de Engenharia Agrícola e Ambiental, 15(8), 794-800.

Heemst, H.D.G., 1986. The influence of weed competition on crop yield. Agricultural Systems, 18(2), 81-83.

Miranda, J.H., Bérgamo, L.R., Reis, J.B.RS., Cruciani, D.E., Duarte, S.N., 2010. Distribuição da concentração de potássio no solo em lisímetros cultivados com amendoim. Engenharia Agrícola, 30(2), 253-263.

Parreira, M.C., Alves, P.L.C.A., Peñaherrera-Colina, L.A., 2011. Influencia de las malezas sobre El cultivo de frijol en función de espaciamiento y de la densidad de plantas. Planta Daninha, 29(4), 761-769.

Pitelli, R.A., 1985. Interferência das plantas daninhas nas culturas agrícolas. Informativo Agropecuário, 11(29), 16-27.

Raij, B., Cantarela, H., Quaggio, J.A., Furlani, A.M.C., 1996. Recomendações de adubação e calagem para o Estado de São Paulo, segunda ed. Campinas-SP, IAC (Boletim Técnico, 100).

Ratnakumar, P., Vadez, V., 2011. Groundnut (Arachis hypogaea) genotypes tolerant to intermittent drought maintain a high harvest index and have small leaf canopy under stress. Functional Plant Biology, 38(12), 1016-1023.

Sant'Ana, E.V.P., Santos, A.B., Silveira, P.M., 2010. Adubação nitrogenada na produtividade, leitura spad e teor de nitrogênio em folhas de feijoeiro. Pesquisa Agropecuária Tropical, 40(4), 491-496.

Santos, J.B., Silveira, T.P., Coelho, P.S., Costa, O.G., Matta, P.M., Silva, M.B., Drumond Neto, A. P., 2010. Interferência de plantas daninhas na cultura do quiabo. Planta Daninha, 28(2), 255-262.

Santos, R.C., Freire, R.M.M., Lima, L.M., Zagonel, G.F., Costa, B.J., 2012. Produtividade de grãos e óleo de genótipos de amendoim para o mercado oleoquímico. Revista Ciência Agronômica, 43(1), 72-77.

Sharwood, R.E., Crous, K.Y., Whitney, S.M., Ellsworth, D.D., Ghannoum, O., 2016. Linking photosynthesis and leaf N allocation under future elevated $\mathrm{CO}_{2}$ and climate warming in Eucalyptus globulus. Journal of Experimental Botany, 68(5), 1-11. 
Silva, F.A.S., Azevedo, C.A.V., 2002. Versão do programa computacional Assistat para o sistema operacional Windows. Revista Brasileira de Produtos Agroindustriais, 4(1), 71-78.

Silva, W.B., Petter, F.A., Lima, L.B., Andrade, F.R., 2013. Desenvolvimento inicial de Urochloa ruziziensis e desempenho agronômico da soja em diferentes arranjos espaciais no cerrado Mato-Grossense. Bragantia, 72(2), 146153.
Tellah, S., Badiani, M., Trifilo, P., Lo Gullo, M.A., Ounane, G., Ounane, S.M., Sorgona, A., 2014. Morpho-physiological traits contributing to water stress tolerance in a peanut (Arachis hypogaea L.) landraces collection from the Algerian Maghreb. Agrochimica, 58(2), 126-147.

Vidal, R.A., Merotto Junior, A., 2001. Herbicidologia. Porto Alegre-RS, Evangraf. 